\title{
MEMES NA SALA DE AULA DE LÍNGUA INGLESA: VIVÊNCIAS FORMATIVAS EM UMA EDUCAÇÃO CIBERATIVISTA
}

Mariana Lettieri Ferreira Lucila Pesce ${ }^{(*)}$

\section{INTRODUÇÃO}

Nos tempos contemporâneos não há como ignorar o fato de que as práticas sociais têm, em grande medida, se erguido em meio a um contexto híbrido. Redes e ruas engendram-se cada vez mais (SANTAELLA, 2017). São inúmeros os exemplos. Um dos mais recentes e emblemáticos é a presença massiva de estudantes, professores, pesquisadores, pais e cidadãos, de modo geral, nas ruas de todos os estados brasileiros e no Distrito Federal, no dia 15 de maio de 2019, com um importante pleito: defesa da educação e da ciência. Este movimento, embora iniciado e mobilizado nas redes sociais, partiu para as ruas, sendo, portanto, emblemático do hibridismo que se ergue em meio às práticas sociais contemporâneas.

Esse cenário sociohistórico converge com o campo de reflexão da proposta da seção temática intitulada: "Educação ativista na cibercultura: experiências plurais". E é no bojo da supracitada seção temática que o presente artigo analisa uma vivência formadora realizada nas aulas de língua inglesa, junto a alunos do nono ano do Ensino Fundamental, em uma Escola Municipal de Ensino Fundamental (EMEF), na zona norte da cidade de São Paulo.

Trata-se de pesquisa qualitativa de caráter exploratório, cujo delineamento do quadro teórico de referência ergue-se em meio a três campos conceituais: net-ativismo (JUNQUEIRA; PAZ, 2016; BABO, 2017), empoderamento (FREIRE, 1981, 1992; FREIRE; SHOR, 1986), pedagogia dos multiletramentos (ROJO; MOURA, 2012; ROJO; BARBOSA, 2015), como segue.

\section{Quadro teórico de referência}

Antes de iniciar o relato analítico sobre a pesquisa exploratória supracitada, faz-se necessária explicitar que o referencial teórico da investigação se ergue em três campos conceituais: net-ativismo, empoderamento Freireano e pedagogia dos multiletramentos.

\footnotetext{
(*) Mariana L. Ferreira. Mestranda em Educação no PPGE da Universidade Federal de São Paulo (UNIFESP). Bacharel e licenciada em Letras - Inglês e Português pela Universidade de São Paulo (USP). Orcid: < https://orcid.org/0000-0002-9024-736X>.
}

Lucila Pesce. Doutora em educação pela PUC-SP, com pós-doutorado em Filosofia e História da Educação (Unicamp). Professora associada do Depto de Educação e credenciada no PPGE. Orcid: 〈http://orcid.org/0000-0002-2562-2012>. 
Ao asseverar que as práticas de linguagem são sempre situadas, Rojo e Barbosa (2015) sinalizam que, na atualidade, tais práticas sociais frequentemente erguem-se em meio a culturas em rede, pela mediação das Tecnologias Digitais da Informação e Comunicação (TDIC). Nesse movimento, as pesquisadoras alertam que, para qualificar a participação dos estudantes nas práticas sociais veiculadas na web, a escola deve promover "[...] experiências significativas com produções de diferentes culturas e com práticas, procedimentos e gêneros que circulam em ambientes digitais [...]" (ibid., p. 135). Com isto em mente, a pesquisa exploratória que foi desenvolvida procurou trabalhar com os memes, de maneira a promover uma experiência significativa utilizando-se de um gênero que circula em ambientes digitais e trazendo-o para o "chão da escola".

O net-ativismo vem sendo estudado por diversos pesquisadores, uma vez que a internet e as redes sociais têm se mostrado como um espaço profícuo para a mobilização de grupos, de maneira a organizar ações coletivas. "Esta rede colaborativa proporcionada pelas tecnologias digitais coloca em cena novos mediadores e produtores de narrativas." (BENTES, 2009 apud PAZ; JUNQUEIRA, 2016, p.55). Posteriormente, relacionaremos a importância do conceito de net-ativismo na educação contemporânea e sua complementaridade com o empoderamento Freireano e a pedagogia dos multiletramentos, uma vez que, nesta pesquisa de caráter exploratório, observou-se que os alunos passaram de meros receptores a produtores que poderão transpor seus conhecimentos e agir em outras situações, de maneira protagonista. Para Babo (2017):

O net-ativismo - mediativismo ou mobilizações informacionais - assenta-se num novo tipo de sociabilidade reticular, que se desenvolve nas mídias participativas ou nas redes sociais digitais conectadas (internet e dispositivos móveis de conexão: tablet, smartphone, iPod, etc.), em que as possibilidades de expressão e disseminação ilimitada de mensagens são usadas para novas modalidades de interação, associação e mobilização pública, que vão das mobilizações cívicas de protesto às terroristas. A internet se torna, desse modo, arena de modificação da ação coletiva. (BABO, 2017 , p. 83 - grifo das autoras do artigo).

Ou seja, se levarmos em consideração este caráter coletivo do net-ativismo, não podemos deixar de associá-lo ao conceito de empoderamento proposto por Freire (1986), em seus diálogos com Ira Shor no livro "Medo e Ousadia - O cotidiano do professor". Baquero (2012) faz uma leitura muito pertinente, ao asseverar que, para o educador brasileiro, o empoderamento (empowerment) deve ocorrer na esfera do coletivo, não apenas individual, "o que implica favorecer sua capacidade pessoal e social de articulação com outros sujeitos, com vistas a transformar as relações sociais e, por conseguinte, as relações de poder.” (BAQUERO, 2012 apud JOAQUIM; PESCE, 2017, p. 190). Assim sendo, 
[...] toda ação para inclusão digital, cujo objetivo seja inserir os sujeitos na cibercultura a fim de emancipá-los e de desequilibrar as relações de poder na sociedade, deve ser pensado como um movimento de classe, um movimento libertador. Segundo Freire e Shor (1986), não basta empoderar um aluno ou um grupo de alunos, pois a emancipação pessoal não é suficiente, em uma perspectiva de educação para a transformação social. (JOAQUIM; PESCE, 2017, p.192 - grifos dos autores deste artigo).

Em convergência com Baquero (2012), Pesce e Bruno (2015) salientam que o conceito de empoderamento em Freire $(1981$; 1992) ampara-se na dimensão coletiva. No livro dialogal com Ira Shor, Freire (1986) esclarece que o empoderamento, se situado em uma perspectiva colegiada, consubstancia-se como elemento fundamental à promoção das transformações sociais, pela contribuição à construção da autonomia dos grupos sociais. É o que se pode inferir do excerto a seguir:

Mesmo quando você se sente, individualmente, mais livre, se esse sentimento não é um sentimento social, se você não é capaz de usar sua liberdade recente para ajudar os outros a se libertarem através da transformação da sociedade, então você só está exercitando uma atitude individualista no sentido do empowerment ou da liberdade (FREIRE; SHOR, 1986, p. 135).

O conceito de empoderamento, na acepção freireana do termo, destaca a relevante contribuição da Educação, para promover práticas sociais voltadas à emancipação de grupos sociais desfavorecidos, precisamente pelo trabalho desenvolvido junto ao saber socialmente legitimado.

Muitas das considerações de Freire dialogam com a ideia de letramentos, especialmente a educação crítica, que focaliza as práticas sociais e os sujeitos. Dessa maneira, é importante que pensemos também na pedagogia dos multiletramentos.

Segundo Rojo (2012), em 1996 um grupo de pesquisadores dos letramentos se reuniram na cidade de Nova Londres nos Estados Unidos (grupo este que ficou conhecido como "Grupo de Nova Londres") e produziram um manifesto cujo título é "A Pedagogy of Multiliteracies Designing Social Futures" e:

Nesse manifesto o grupo afirmava a necessidade de a escola tomar a seu cargo (daí a proposta de uma "pedagogia") os novos letramentos emergentes na sociedade contemporânea, em grande parte - mas não somente - devidos às novas $\operatorname{TICS}^{1}$, e de levar em conta e incluir nos currículos a grande variedade de culturas já presentes nas

\footnotetext{
${ }^{1}$ Tecnologias da Informação e da Comunicação.
} 
salas de aula de um mundo globalizado e caracterizada pela intolerância na convivência com a diversidade cultural, com a alteridade. (ROJO, 2012, p.12)

Dessa forma, os multiletramentos possuem o prefixo "multi" devido a multiculturalidade e multimodalidade (múltiplas semioses). A partir deste conceito, o Grupo de Nova Londres (THE NEW LONDON GROUP, 2000, p.35) apresenta a proposta de uma pedagogia dos multiletramentos como sendo uma integração de quatro fatores, a saber:

$\rightarrow$ Prática situada, ou seja, uma imersão na cultura dos alunos, de forma que eles possam ser responsáveis pelo próprio processo de aprendizagem.

$\rightarrow$ Instrução aberta, que consiste em “[...] uma análise sistemática e consciente dessas práticas vivenciadas e desses gêneros e designs familiares ao alunado e de seus processos de produção e de recepção.” (ROJO, 2012, p.30)

$\rightarrow$ Enquadramento crítico, em que os alunos possam refletir sobre a prática situada e a instrução aberta estabelecendo relações com aspectos históricos, sociais, políticos, ideológicos, culturais, para que possam desnaturalizar pensamentos e ideias.

$\rightarrow$ Prática transformadora, de modo que os educandos terminem/saiam da atividade transformados de alguma forma e que possam agir em outros contextos para transformá-los.

Dessa forma, parece ser necessário que a escola repense suas práticas pedagógicas, de maneira a incorporar o net-ativismo em sala de aula, utilizando o espaço da internet como um local de ação coletiva e modificadora, uma vez que o net-ativismo estabelece diálogo com os pressupostos da pedagogia dos multiletramentos, em especial no que diz respeito a uma prática transformadora. Em outras palavras é importante que sejam promovidas vivências formadoras que dialoguem com a perspectiva ativista, tomadas as devidas proporções (afinal estamos falando do espaço escolar). É importante que tanto o aluno quanto o professor percebam a potência das redes para promoção das mais variadas causas.

Os três conceitos expostos anteriormente - net-ativismo, empoderamento e pedagogia dos multiletramentos - dialogam e até certo ponto se complementam. Isso porque, apesar de poder ser usado para fins negativos, como o terrorismo, a pedofilia, os fake News, o discurso de ódio, entre outros, o net-ativismo não deixa de ser uma prática que emancipa os sujeitos e os empodera coletivamente e este empoderamento acaba sendo como o definido por Freire (1986), uma atividade social, ligada à classe social, mas não em sentido estreito. No dizer do patrono da educação brasileira:

Isto faz do empowerment muito mais do que um invento individual ou psicológico. Indica um processo político das classes dominadas que buscam a própria liberdade da 
dominação, um longo processo histórico de que a educação é uma frente de luta. (FREIRE, 1986, p. 138).

Os três campos conceituais ora apresentados articulam-se às considerações de Ribeiro e Santos (2018) sobre a formação do ciberautorcidadão. Preocupadas com os modos pelos quais a autoria se apresenta nas atividades educativas dos sujeitos, ao longo da vida, as autoras sinalizam que as "[...] práticas formativas nas quais os praticantes culturais expressam suas opiniões, seus medos, seus desejos etc., são expressão de cidadania autorizada no espaçotempo da cibercultura" (RIBEIRO; SANTOS, 2018, p. 580). Nessa perspectiva, as pesquisadoras advertem que os processos de formação demandam que os sujeitos sociais estejam implicados com os contextos de formação que se lhes apresentam no cotidiano. Esse foi o movimento buscado na atividade ora analisada.

\section{Aportes metodológicos}

Primeiramente, urge considerar que a pesquisa exploratória ora relatada situa-se como uma primeira aproximação do objeto de investigação da pesquisa em desenvolvimento, no Programa de Pós-graduação em Educação de uma universidade federal no estado de São Paulo.Desse modo, o objetivo principal de analisar esta atividade proposta a uma de suas turmas, é articular os conceitos teóricos supracitados ao seu trabalho no dia a dia escolar.

O presente artigo emana de uma pesquisa qualitativa (BOGDAN; BIKLEN, 1994) de caráter exploratório.

No que se refere à abordagem metodológica, a pesquisa pode ser classificada como sendo de natureza qualitativa, pela atenção dada aos princípios e pressupostos subjacentes às cinco características apontadas por Bogdan e Biklen (1994):

- o ambiente natural é a fonte direta dos dados e o pesquisador é o instrumento principal, uma vez que a pesquisa foi realizada pela professora-pesquisadora em uma de suas turmas na escola municipal de ensino fundamental (EMEF) que trabalha;

- a investigação qualitativa é descritiva. Assim sendo, na pesquisa em tela - procurou-se descrever a atividade, seus desdobramentos e resultados;

- há mais interesse pelo processo do que pelos resultados, considerando que esta pesquisa é um recorte de uma pesquisa mais ampla que está em fase de desenvolvimento e dá especial atenção à observação do processo da atividade; 
- tende-se a analisar os dados de forma indutiva - as notas de campo da professorapesquisadora, os depoimentos dos alunos e as produções dos alunos foram analisados à luz dos conceitos supracitados

- o significado é de importância vital na abordagem qualitativa - daí a atenção dada ao sentido e ao ignificado atribuído pelos estudantes envolvidos na pesquisa.

No tocante à tipologia da pesquisa qualitativa, a pesquisa assume um caráter exploratório, uma vez que, segundo Gil (2002 [1987]), “estas pesquisas têm como objetivo proporcionar maior familiaridade com o problema, com vistas de torná-lo mais explícito ou a construir hipóteses." (p.41). Neste caso, o problema que esta pesquisa visava explorar era como o trabalho com um gênero familiar para os estudantes (memes), mediante proposição de memes pelos alunos, poderia empoderá-los para olharem criticamente e, na medida do possível, transformarem suas realidades em outras situações.

Em relação aos instrumentos de produção de dados, a pesquisa valeu-se das notas de campo da professora-pesquisadora, a primeira autora do presente artigo, e dos registros dos depoimentos dos estudantes que dela participaram.

A questão que motivou a pesquisa, portanto, foi: Em que medida a atividade proposta dialoga com a pedagogia dos multiletramentos, o net-ativismo e o empoderamento freireano?

\section{RELATO ANALÍTICO DA VIVÊNCIA FORMADORA}

A vivência formadora foi proposta por uma professora de inglês na disciplina de língua inglesa a uma turma de nono ano, com 30 alunos, do ensino fundamental em uma EMEF na zona norte da cidade de São Paulo. Em virtude da comemoração do dia de São Patrício (St. Patrick's Day), a professora-pesquisadora, primeira autora do presente artigo, utilizou-se uma atividade didática preparada e sugerida pela editora Richmond ${ }^{2}$. Apesar da proposta da editora ser para o Ensino Médio, a professora-pesquisadora julgou pertinente o trabalho com esta turma, uma vez que a professora-pesquisadora já trabalha com a turma há 2 anos observou que a turma poderia acompanhar bem a atividade, uma vez que as competências e habilidades exigidas já haviam sido trabalhadas em outros momentos em outras atividades.

A vivência formadora, que durou cerca de seis aulas de quarenta e cinco minutos cada, consistia, em um primeiro momento, no trabalho com a data comemorativa de Saint Patrick's Day

\footnotetext{
2 Disponível em: <http://www.richmond.com.br/filesrs/richmond/2019/erichmond/03/ACTBANK_CELEB_Mar17 SaintPatricksDay_1_EM.pdf $>$.
} 
e, num segundo momento, na discussão acerca dos estereótipos relacionados à imagem do irlandês. Nesta segunda etapa da atividade, consta nas orientações a sugestão de estender a atividade, ao apresentar imagens relacionadas ao brasileiro através de um link do site Huffpost ${ }^{3}$ e uma extensão com a produção de memes para enfrentar as imagens estereotipadas associadas ao brasileiro. Segundo o dicionário Priberam, um meme é uma "1. Imagem, informação ou ideia que se espalha rapidamente através da internet, correspondendo geralmente à reutilização ou alteração humorística ou satírica de uma imagem."4

Para melhor realizar a pesquisa exploratória, o presente artigo enfoca o segundo momento da atividade formadora, quando é proposta a discussão acerca dos estereótipos. O objetivo desta atividade era um trabalho pautado na pedagogia dos multiletramentos através dos quatro fatores integrados - prática situada, instrução aberta, enquadramento crítico e prática transformadora - em que os estudantes pudessem, ao final, produzir um gênero que lhes é familiar (meme) e como a sua produção poderia empoderá-los para procederem a uma leitura crítica das suas circunstâncias e, na medida do possível, transformarem suas realidades em outras situações.

Inicialmente, os alunos foram questionados se sabiam o significado dessa palavra. Alguns responderam que era uma imagem que não refletia a realidade, uma vez que se generaliza um povo. Também colocaram em discussão que pode ser uma imagem preconceituosa e que enfatiza os aspectos negativos. Quando a professora-pesquisadora iniciou a discussão a partir das imagens estereotipadas dos irlandeses, muitos alunos não participaram, uma vez que não conheciam o que estava associado a este grupo social. Nesse momento fez-se necessário dar maior enfoque à questão dos estereótipos relacionados aos brasileiros. Ao apresentar o link do Huffpost supracitado, alguns alunos ficaram indignados com algumas das imagens associadas aos brasileiros, uma vez que não conheciam algumas delas e se sentiram munidos de argumentos para a discussão. Posteriormente, a professora-pesquisadora sugeriu que os alunos escolhessem algum estereótipo associado à imagem do brasileiro (eles poderiam utilizar os estereótipos discutidos em sala, bem como pesquisar outros) e que produzissem um meme que se mostrasse contrário a isso. Os alunos poderiam trabalhar individualmente ou em pequenos grupos de até três integrantes.

Oportuno observar que a linguagem do meme já é conhecida pelos alunos, já faz parte das suas práticas de letramento; dessa forma não é necessário explicar o que deve ser feito. Eles se

\footnotetext{
3 Disponível em: <https://www.huffpostbrasil.com/2014/02/12/brazilian-stereotypes-reactions_n_4760578.html?ec carp $=6158915061520206804>$.

4 "Meme", in Dicionário Priberam da Língua Portuguesa [em linha], 2008-2013, https://dicionario.priberam. org/meme [consultado em 17/04/2019].
} 
mostraram bem animados com a proposta e mesmo tendo a necessidade de apresentá-los em inglês, a maioria dos alunos aderiu à vivência formadora. Quando foi sugerido que acessassem o website memegenerator ${ }^{5}$ para suas criações, muitos alunos relataram que já utilizavam esta aplicação no celular.

Os alunos foram enviando os memes por e-mail ou bluetooth para a professorapesquisadora, que imprimiu e produziu um cartaz para a socialização da produção dos alunos para a escola (e os alunos da própria turma, que não tinham visto a produção dos colegas). Muitos alunos ficaram espantados por terem escolhido o mesmo estereótipo, porém utilizaram memes diferentes para se expressar.

É importante dizer também que, na exposição para a escola, foram produzidas legendas em português dos memes, bem como uma explicação da atividade.

Durante a apresentação para a turma, a professora-pesquisadora deixou que os alunos olhassem o cartaz com todos os memes produzidos. Em seguida, enfatizou a alta adesão dos estudantes à produção e a grande preocupação com a boa realização da atividade: muitos deles (porém nem todos) perguntaram à professora-pesquisadora se as frases para os memes estavam corretas, antes de entregar a versão final. Depois, abriu-se um espaço para que os alunos opinassem e comentassem a experiência da vivência formadora. Alguns dos comentários foram: "Teacher, memes é comigo mesmo. Adoro!", "Eu uso memes prontos no dia a dia, mas quando você sugeriu o aplicativo, eu não conhecia. Mas achei fácil de usar e fazer os memes por lá.", "Adorei este trabalho, pra mim foi o melhor até agora.”.

Para ilustrar, seguem alguns dos memes elaborados pelos alunos ${ }^{6}$ e o cartaz exposto na unidade escolar. A atividade evidenciou que os alunos, ao realizarem suas produções, aproveitaram a oportunidade para refletir criticamente sobre as questões referentes aos estereótipos associados à imagem do brasileiro no exterior.

\footnotetext{
${ }^{5}$ Disponível em: https://imgflip.com/memegenerator

${ }^{6}$ Para preservar a identidade dos alunos, foram criados nomes fictícios.
} 


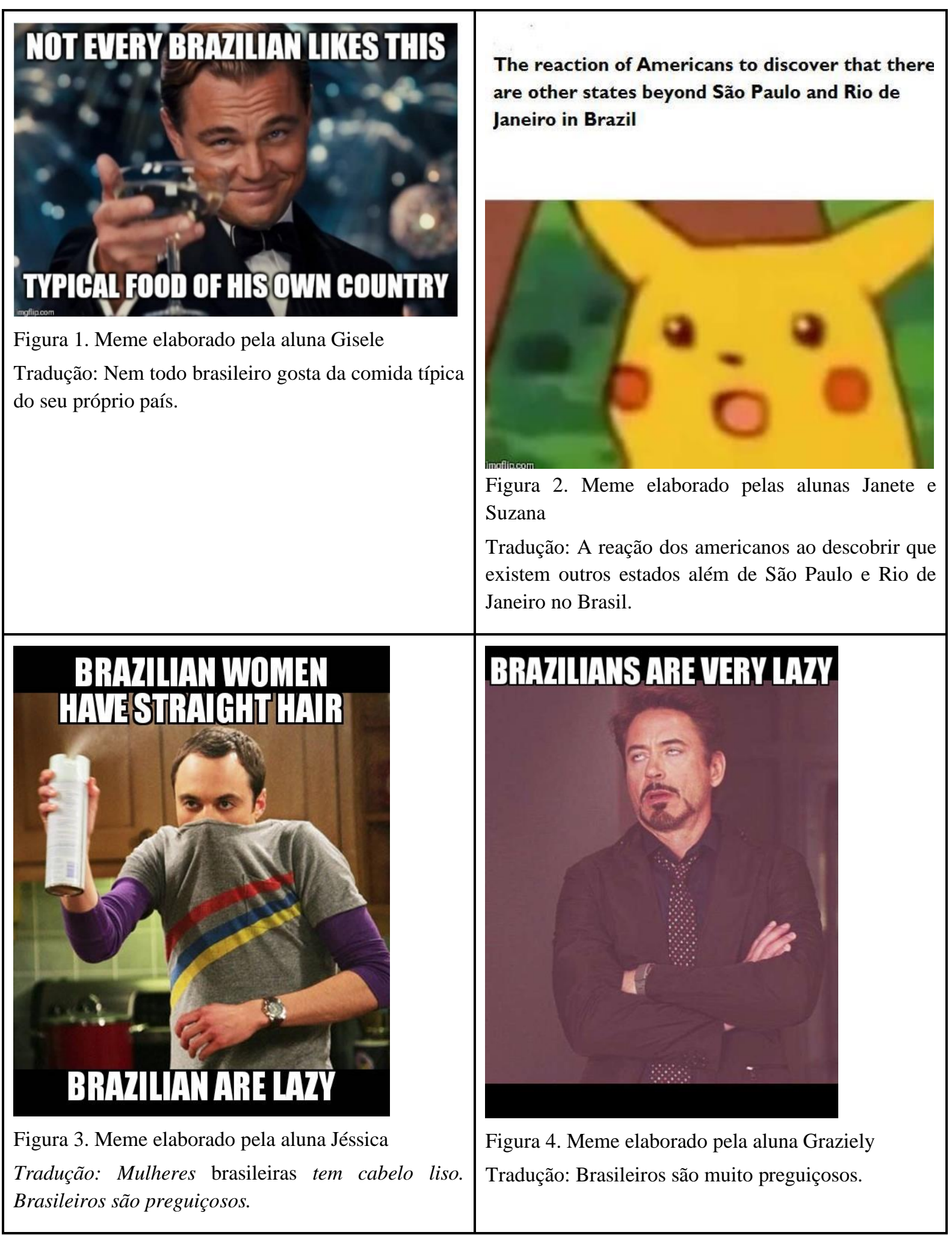




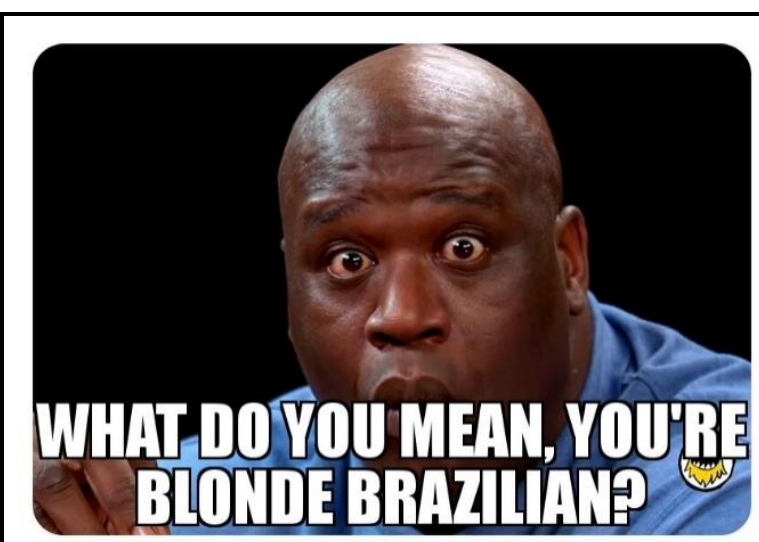

Figura 5. Meme elaborado pelo aluno Kaio

Tradução: Como assim, você é um brasileiro loiro?

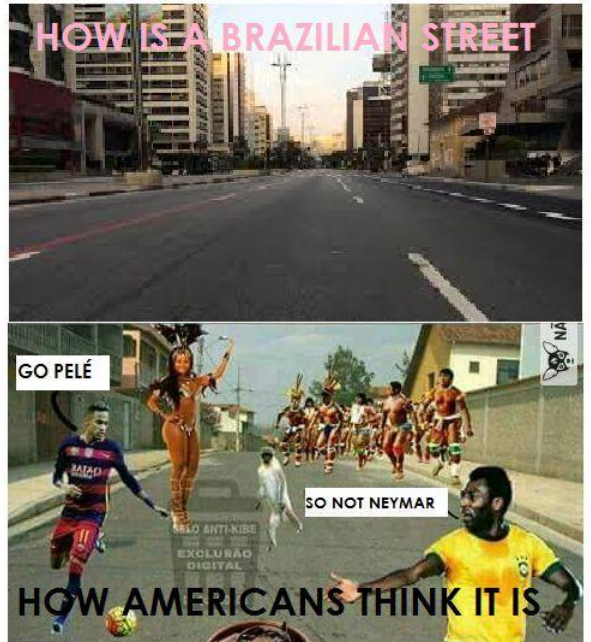

Figura 6. Meme elaborado pelas alunas Alice e Bárbara

Tradução: Como é uma rua no Brasil. / Como americanos pensam que é.

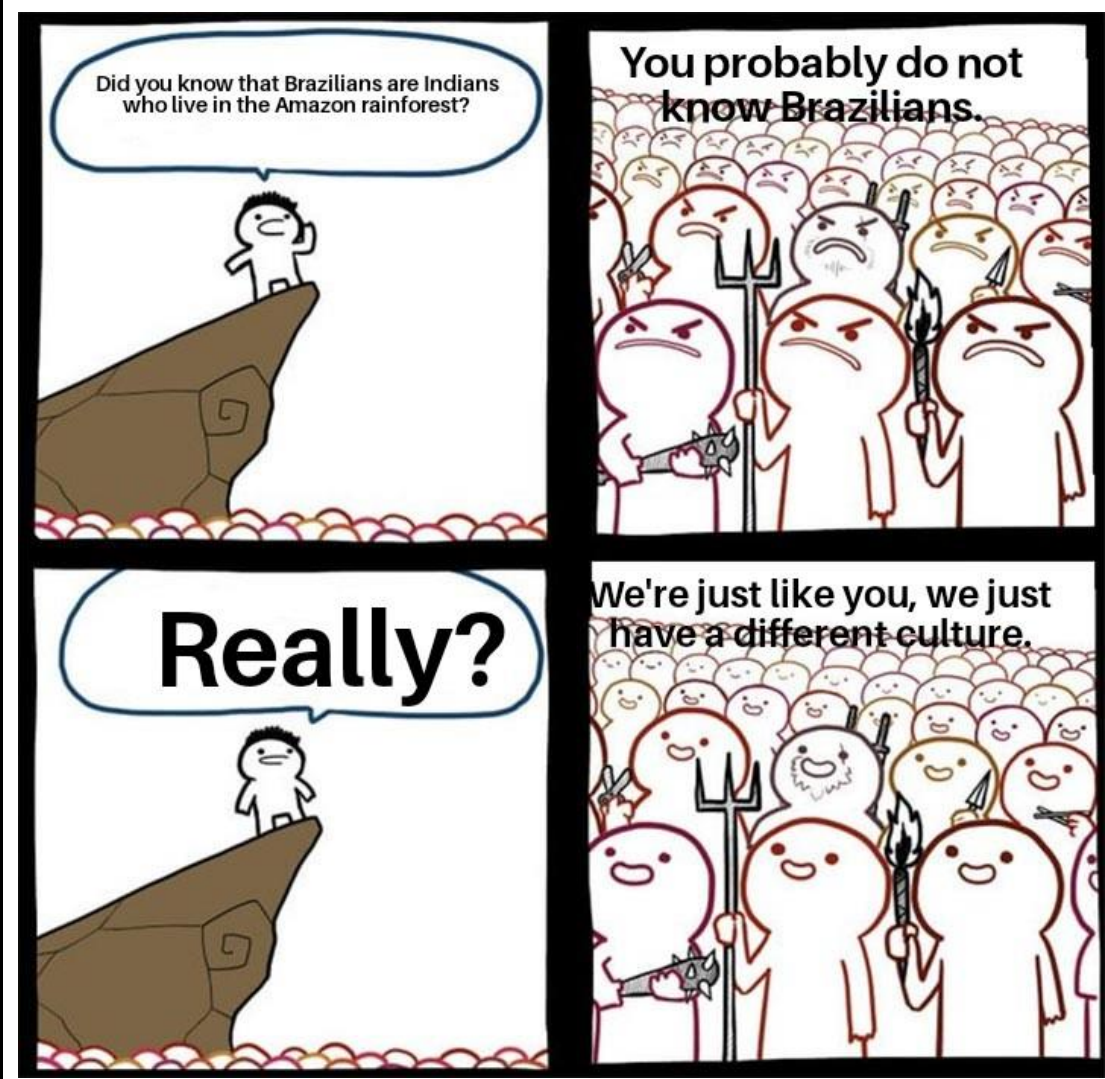

Figura 7. Meme elaborado pela aluna Elvira

Tradução: Vocês sabiam que os brasileiros são índios que moram na floresta Amazônica? / Provavelmente você não conhece os brasileiros. / Sério? / Nós somos como você, apenas temos uma cultura diferente. 


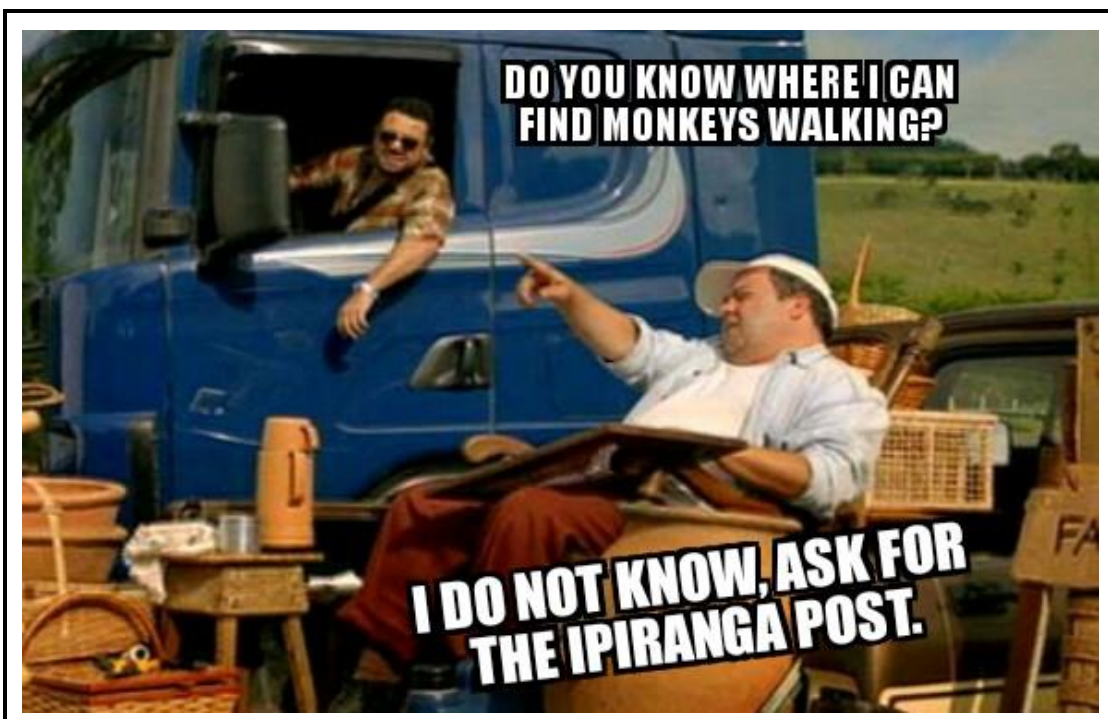

Figura 8. Meme elaborado pelos alunos Márcio, Otávio e Kerlon

Tradução: Você sabe onde posso encontrar macacos andando? / Eu não sei. Pergunte no posto Ipiranga.

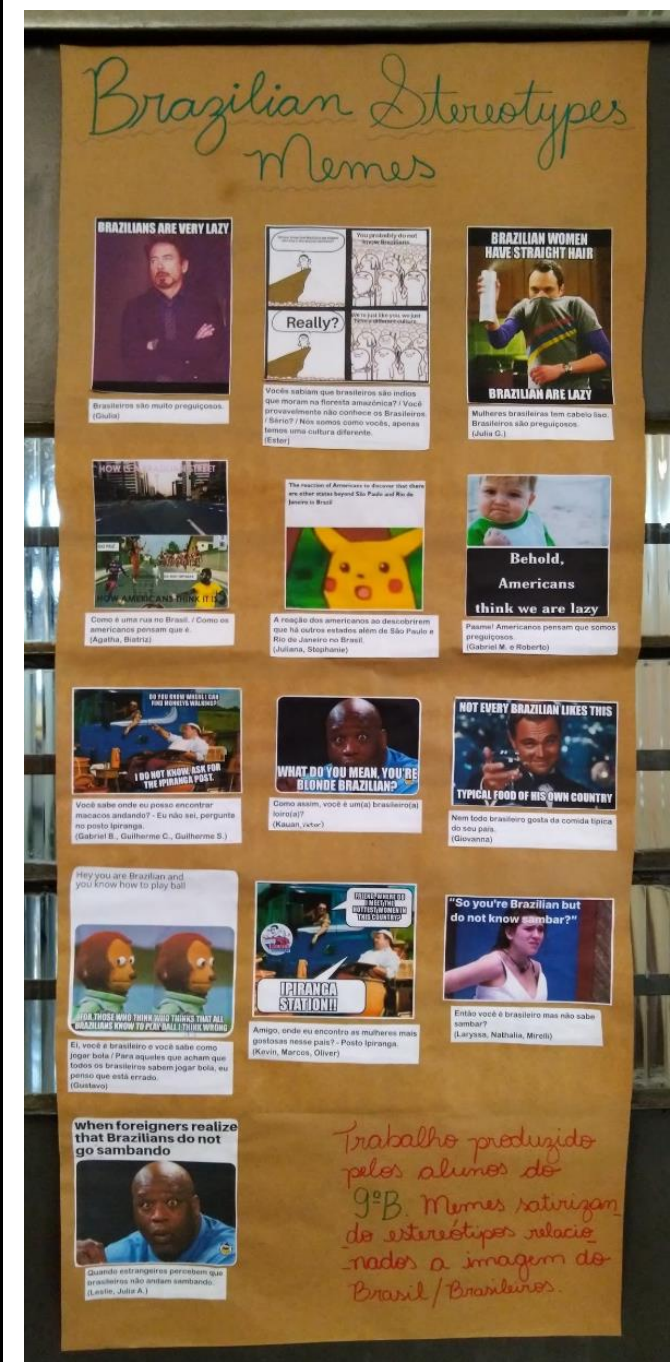

Figura 9. Cartaz elaborado para socialização dos memes produzidos pelos alunos, seguido de tradução de cada um deles. 


\section{PESQUISA EXPLORATÓRIA - DISCUSSÃO DOS RESULTADOS}

Os dados observados indicam que a vivência formadora já apresenta um possível caminho de mudança, conforme comentário da aluna Jéssica": "Eu uso memes prontos no dia a dia, mas quando você sugeriu o aplicativo, eu não conhecia. Mas achei fácil de usar e fazer os memes por lá.”. O depoimento da estudante vai ao encontro da proposta de Bonilla (2010):

Promover a inclusão digital é, na nossa percepção, oportunizar que cada sujeito social possa, efetivamente, participar desse movimento, não sujeitando-se às práticas que o condicionam a mero consumidor, seja de informações, seja de bens, seja de cultura. (BONILLA, p. 57, 2010)

Ao optar por uma metodologia de trabalho pautada pela pedagogia dos multiletramentos, do Grupo de Nova Londres (2000), há quatro fatores que devem ser levados em consideração, ao pensar em vivências formadoras segundo esta pedagogia.

1. Prática situada, baseada nas experiências dos estudantes. Na vivência formadora em tela, o trabalho com memes dialoga com as experiências dos discentes.

2. Instruções claras.

3. Enquadramento crítico, em que os alunos possam transpor a atividade, pensando inclusive na sua realidade social. Na vivência formadora ora analisada foi necessário que os alunos refletissem acerca dos estereótipos acerca dos brasileiros no exterior, para que pudessem satirizá-los.

4. Prática transformadora, de forma que os educandos sejam transformados pela atividade e possam transformar a sua realidade a partir disso. Quanto à vivência formadora aqui relatada, o comentário da aluna Jéssica indica que, de certo modo, ela foi transformadora, uma vez que a educanda não conhecia a ferramenta de produção de memes e, a partir da vivência formadora analisada, poderá utilizar-se dela para transformar outros contextos e situações.

Segundo Junqueira e Paz (2016), o net-ativismo promove, através do uso das TDIC, a criação de novos mediadores e produção de narrativas. Nessa perspectiva, os dados da pesquisa exploratória sugerem que os alunos passaram a participar mais ativamente do seu processo de aprendizagem, uma vez que eles refletiram sobre a proposta da professora-pesquisadora e produziram seus próprios memes, criticando os estereótipos dos brasileiros no exterior.

\footnotetext{
${ }^{7}$ Para preservar a identidade dos alunos, todos os nomes são fictícios.
} 
No caso da vivência formadora ora relatada, entretanto, o net-ativismo relaciona-se a uma proposta pedagógica que visa a fomentar que alunos possam vir a exercê-lo em sua essência em outros momentos e espaços. Dessa forma, ao entrarem em contato com este uso da tecnologia para produções autorais, os alunos puderam refletir acerca da aplicação em outras áreas e momentos, conforme o comentário da aluna Jéssica que abre esta seção.

É pertinente, portanto, perceber os pontos de convergência entre os conceitos de netativismo, empoderamento Freireano, no tocante ao trabalho coletivo produzido pelos estudantes, e pedagogia dos multiletramentos, no que se refere aos seus pressupostos ontológicos e gnosiológicos e na contribuição de todos eles à implantação de uma educação voltada ao ativismo, inclusive, no ciberespaço.

Também é relevante pensar que o uso das TDIC na vivência formadora ora analisada não foi adotado apenas para dizer que foram, "essa forma de utilização da tecnologia, segundo Pretto (1996, p. 114), reduz as suas possibilidades e esvazia as TIC de suas características fundamentais, transformando-as em animadoras da velha educação" (PRETTO, 1996, p. 114 apud BONILLA, 2010, p.46). No caso do trabalho com os memes, este gênero do discurso veiculado em suporte digital - tanto a sua produção quanto a distribuição - a professora-pesquisadora, ao incorporá-los na vivência formadora, buscou promover o uso das TDIC em práticas sociais situadas. Ainda que a sua apresentação final tenha sido feita em forma de cartaz, os alunos utilizaram-se do smartphone ou de computadores para produzirem seus memes e compartilharam suas produções com a professorapesquisadora por bluetooth e $e$-mail.

Oportuno observar que, ao propor que os alunos produzissem memes, a professorapesquisadora que conduziu a vivência formadora deixou a possibilidade de os alunos produzirem seus memes de outra forma que não através das tecnologias digitais, uma vez que a necessidade de uso das TDIC poderia vir a excluir algum educando que, por ventura, não possuísse acesso a elas. Apesar dessa proposta, para não excluir qualquer estudante, ao contrário do que a professorapesquisadora imaginou, a adesão dos alunos a esta vivência formadora foi maior do que outros tipos de atividades que não se apoiam nas TDIC, na elaboração do produto final. Nesse movimento, os dispositivos móveis tiveram importância capital na realização das produções discentes. Este achado converge com as considerações de Junqueira e Paz (2016), para quem:

As possibilidades de autoria e construção de narrativas que disputam com o discurso hegemônico da mídia, potencializada pelo crescente acesso e uso dos dispositivos móveis em rede para a produção, veiculação, recepção e interação podem indicar um 
novo contexto no qual são forjados processos formativos contemporâneos.

(JUNQUEIRA; PAZ, 2016, p.71)

Os achados da pesquisa sugerem que a vivência formadora ora relatada qualificou a participação dos estudantes nas práticas sociais situadas e veiculadas na web, em conformidade com as considerações de Rojo e Barbosa (2015). Assim sendo, os achados da pesquisa sugerem que a vivência formadora em tela trouxe alguma contribuição para o delineamento de práticas educativas erguidas em meio aos pressupostos de uma educação ativista na cibercultura (RIBEIRO; SANTOS, 2018).

\section{CONSIDERAÇÕES FINAIS:}

O presente artigo teve como objetivo apresentar uma pesquisa qualitativa de caráter exploratório sobre uma vivência formadora desenvolvida junto a estudantes do nono ano do Ensino Fundamental, nas aulas de língua inglesa, em uma Escola Municipal, na cidade de São Paulo. O argumento teórico do artigo ergue-se em meio à seguinte tríade conceitual: net-ativismo, empoderamento, pedagogia dos multiletramentos.

Esperamos que o relato analítico ora apresentado possa, de algum modo, dar sua singela contribuição para o adensamento do debate sobre práticas pedagógicas pautadas em uma educação ativista na cibercultura (RIBEIRO; SANTOS, 2018).

Como pudemos observar, os estudantes se engajaram na vivência formadora como um todo, desde as discussões até os memes produzidos, conforme o relato supracitado. O forte engajamento dos alunos, em todas as etapas da vivência formadora revela que a escola, através de uma prática social situada e do trabalho com os multiletramentos, pode promover um espaço para aprendizagens significativas, como bem nos ensinam Munarim, Girardello e Munarim (2015):

Se a dimensão da produção existe para fortalecer um determinado projeto de sociedade, a formação dos professores para o 'uso' das tecnologias não deve se resumir apenas ao seu uso em sala de aula, mas também a momentos de reflexão em que eles possam conhecer, compreender e problematizar junto aos estudantes as dimensões políticas e econômicas que estão em jogo na produção dessas tecnologias.

Daí a importância de que professores e estudantes saibam buscar informações, participem, produzam conteúdos próprios, planejem ações, incluam essas ferramentas digitais no cotidiano das escolas como mais um espaço de criação e expressão delas e dos sujeitos que com elas interagem. Que crianças, jovens, pais e professores possam utilizar essas tecnologias como um importante instrumento 
para suas buscas, suas lutas e seus questionamentos. (MUNARIM; GIRARDELLO; MUNARIM, 2015, p. 11 - grifo dos autores do artigo).

Em concordância com os autores supracitados, destacamos a importância de que a escola seja pensada como espaço de criação e expressão dos sujeitos sociais. E, nesse movimento, que as TDIC possam se consubstanciar como dispositivos e interfaces cada vez mais presentes no cotidiano escolar, em uma perspectiva que contribua para a emancipação dos discentes e para a construção de uma sociedade cada vez mais consciente e crítica. 


\section{REFERÊNCIAS}

BONILLA, Maria Helena. Políticas públicas para inclusão digital nas escolas. Motrivivência, ano XXII, n. 34, p. 4060, jun. 2010. Disponível em: http://www.periodicos.ufsc.br/index.php/motrivivencia/article/view/17135 Acesso em: 16 mai. 2019.

BABO, Isabel. Redes e ativismo. In: DI FELICE, Massimo; PEREIRA, Eliete; ROZA, Erick (orgs.). Net-ativismo: redes digitais e novas práticas de participação. Campinas: Papirus: 2017. p. 77-88.

BAQUERO, Rute. Empoderamento: instrumento de emancipação social? Uma discussão conceitual. Revista Debates (UFRGS), Porto Alegre, v. 6, n. 1, p. 173-187, jan.- abr. 2012. Disponível em: _ https://seer.ufrgs.br/debates/ article/ viewFile/26722/17099 Acesso em: 16 mai. 2019.

BOGDAN, Robert; BIKLEN, Sari. Investigação qualitativa em educação: uma introdução à teoria e aos métodos. Trad. Maria João Alvarez, Sara Bahia dos Santos, Telmo Mourinho Baptista. Porto: Porto Editora, 1994. (Coleção Ciências da Educação).

THE NEW LONDON GROUP. A pedagogy of Multiliteracies designing social futures. in: COPE, Bill; KALANTZIS, Mary (orgs.). Multiliteracies: literacy learning and the design of social futures. Londres/Nova York: Routledge, 2000.

FREIRE, Paulo. Pedagogia do oprimido. Rio de Janeiro: Paz e Terra, 1981.

Pedagogia da esperança: um reencontro com a pedagogia do oprimido. Rio de Janeiro: Paz e Terra, 1992.

; SHOR, Ira. Medo e ousadia: o cotidiano do professor. Rio de Janeiro: Paz e Terra, 1986.

GIL, Antonio Carlos. Como elaborar projetos de pesquisa. 4. ed. - São Paulo: Atlas, 2002.

JOAQUIM, Bruno dos Santos; PESCE, Lucila. Inclusão digital, empoderamento e educação ao longo da vida: conceitos em disputa no campo da Educação de Jovens e Adultos. Crítica Educativa (Sorocaba/SP), v. 3, n. 3, p. 185-199, ago./dez.2017. Disponível em: http://www.criticaeducativa.ufscar.br/index.php/criticaeducativa/article/view/244/361 Acesso em: 16 mai. 2019

JUNQUEIRA, Eduardo; PAZ, Tatiana. Ativismo e dispositivos móveis em redes: narrativas sobre o cabelo crespo no YouTube. In: COUTO, Edvaldo; PORTO, Cristiane; SANTOS, Edmea (orgs.). App-learning: experiências de pesquisa e formação. Salvador: EDUFBA, 2016. p. 51-74.

MUNARIM, Iracema; GIRARDELLO, Gilka; MUNARIM, Antonio. Educação do campo e políticas públicas para “inclusão digital" em escolas do campo do Brasil. In: Anais da XXXVII Reunião Anual da ANPED: PNE - tensões e perspectivas para a educação pública brasileira, 2015, Florianópolis: Ed UFSC, 2015. v. 1. p. 1-16. Disponível em: http://37reuniao.anped.org.br/wp-content/uploads/2015/02/Trabalho-GT16-4053.pdf Acesso em: 17 mai. 2019

PESCE, Lucila; BRUNO, Adriana R. Educação e inclusão digital: consistências e fragilidades no empoderamento dos grupos sociais. Dossiê - In/exclusão digital e Educação. Educação (PUC RS). v. 38, n. 03, set.-dez. 2015. p. 349-357. Disponível em: http://revistaseletronicas.pucrs.br/fo/ojs/index.php/faced/article/view/21779 Acesso em: 16 mai. 2019

RIBEIRO, Mayara; SANTOS, Edmea. Ciberautocidadão: contribuição para pensarfazer a formação docente e discente na cibercultura. Revista E-Curriculum (PUCSP), v. 12, p. 565-587, 2018. Disponível em: https://revistas.pucsp.br/ curriculum/article/view/36873/25800 Acesso em: 16 mai. 2019

ROJO, Roxane; MOURA, Eduardo (orgs.). Multiletramentos na escola. São Paulo: Parábola Editorial, 2012.

ROJO, Roxane; BARBOSA, Jacqueline. Hipermodernidade, multiletramentos e gêneros discursivos. São Paulo: Parábola Editorial, 2015. (Série Estratégias de Ensino 51).

SANTAELLA, Lucia. Política nas redes e nas ruas. In: DI FELICE, Massimo; PEREIRA, Eliete; ROZA, Erick (orgs.). Net-ativismo: redes digitais e novas práticas de participação. Campinas: Papirus: 2017. p. 89-102. 


\section{RESUMO}

O artigo relata uma pesquisa qualitativa de caráter exploratório sobre uma atividade desenvolvida junto a estudantes do nono ano do Ensino Fundamental, nas aulas de língua inglesa, em uma Escola Municipal, na cidade de São Paulo. A pesquisa engendra três campos conceituais: net-ativismo, empoderamento, pedagogia dos multiletramentos. Quanto aos instrumentos de produção de dados, a investigação vale-se das notas de campo da pesquisadora e dos registros de depoimentos de estudantes que participaram da atividade em análise. Os achados da pesquisa sugerem que a atividade em tela qualificou a participação dos estudantes nas práticas sociais veiculadas na esfera digital, trazendo contribuições a práticas educativas erguidas em meio aos pressupostos da educação ativista na cibercultura.

Palavras-chave: Ensino de língua inglesa, memes, pedagogia dos multiletramentos.

\section{MEMES IN THE ENGLISH-LANGUAGE CLASSROOM: FORMATIVE EXPERIENCES IN A CYBERACTIVIST-EDUCATION}

\section{ABSTRACT}

The article reports a qualitative research of an exploratory nature about an activity developed with students of the ninth grade of Elementary School, in English classes, in a Municipal School, in the city of São Paulo. The research articulates three conceptual fields: net-activism, empowerment, pedagogy of multiliteracies. As for the instruments of data production, the research uses the field notes of the researcher and the records of testimonies of students who participated in the activity under analysis. The research findings suggest that the activity qualified students' participation in the social practices carried out in the digital sphere, bringing contributions to educational practices according to the principles of activist education in cyberculture.

Keywords: Teaching of the English language, memes, pedagogy of multiliteracies.

\section{MEMES EN EL AULA DE LENGUA INGLESA: VIVENCIAS FORMATIVAS EN UNA EDUCACIÓN CIBERATIVISTA}

\section{RESÚMEN}

El artículo relata una investigación cualitativa de carácter exploratorio sobre una actividad desarrollada junto a estudiantes del noveno año de la Enseñanza Fundamental, en las clases de lengua inglesa, en una Escuela Municipal, en la ciudad de São Paulo. La investigación engendra tres campos conceptuales: net-activismo, empoderamiento, pedagogía de los multiletramentos. En cuanto a los instrumentos de producción de datos, la investigación se vale de las notas de campo de la investigadora y de los registros de testimonios de estudiantes que participaron de la actividad en análisis. Los hallazgos de la investigación sugieren que la actividad calificó la participación de los estudiantes en las prácticas sociales vehiculadas en la esfera digital, trayendo aportaciones a prácticas educativas erguidas en medio de los presupuestos de la educación activista en la cibercultura

Palabras clave: Enseñanza de lengua inglesa, memes, pedagogía de los multiletramentos

Submetido em Março de 2019 Aprovado em Outubro de 2019 